\title{
Physiological characteristics of classical ballet
}

\author{
PETER G. SCHANTZ and PER-OLOF ÅSTRAND \\ Department of Physiology III, Karolinska Institutet, Lidingövägen 1, \\ S-114 33 Stockholm, SWEDEN
}

\begin{abstract}
SCHANTZ, PETER G. and PER-OLOF ȦSTRAND. Physiological characteristics of classical ballet. Med. Sci. Sports Exerc., Vol. 16, No. 5 , pp. $472-476,1984$. The aerobic and anaerobic energy yield during professional training sessions ("classes") of classical ballet as well as during rehearsed and performed ballets has been studied by means of oxygen uptake, heart rate, and blood lactate concentration determinations on professional ballet dancers from the Royal Swedish Ballet in Stockholm. The measured oxygen uptake during six different normal classes at the theatre averaged about $35-45 \%$ of the maximal oxygen uptake, and the blood lactate concentration averaged $3 \mathrm{mM}(\mathrm{N}=6)$. During 10 different solo parts of choreographed dance (median length $=1.8 \mathrm{~min}$ ) representative for moderately to very strenuous dance, an average oxygen uptake (measured during the last minute) of $80 \%$ of maximum and blood lactate concentration of $10 \mathrm{mM}$ was measured $(\mathrm{N}=10)$. In addition, heart rate registrations from soloists in different ballets during performance and final rehearsals frequently indicated a high oxygen uptake relative to maximum and an average blood lactate concentration of $11 \mathrm{mM}(\mathrm{N}=5)$. Maximal oxygen uptake, determined in $1971(\mathrm{~N}=11)$ and $1983(\mathrm{~N}=13)$ in two different groups of dancers, amounted to on the average 51 and $56 \mathrm{ml} \cdot \mathrm{min}^{-1} \cdot \mathrm{kg}^{-1}$ for the females and males, respectively. In conclusion, classical ballet is a predominantly intermittent type of exercise. In choreographed dance each exercise period usually lasts only a few minutes, but can be very demanding energetically, while during the dancers' basic training sessions, the energy yield is low.
\end{abstract}

DANCE, OXYGEN UPTAKE, HEART RATE, BLOOD LACTATE CONCENTRATION

Classical ballet has existed for more than a century. Nowadays, it is danced by a great number of recreational dancers, ballet students, and professional dancers; however, there are few reported physiological studies. In two studies $(2,6)$, indirect methods were used to evaluate the aerobic energy yield during stage performance, and in another investigation (3) the oxygen uptake during ballet class exercises was measured. The aim of the present study was to illuminate the aerobic and anaerobic energy yield during normal professional ballet lessons, as well as during rehearsals and stage performances.

\section{METHODS}

Subjects. Professional ballet dancers from the Royal Swedish Ballet in Stockholm participated in the study

Submitted for publication October, 1983.

Accepted for publication March, 1984. which was undertaken primarily during 1983 . They had been dancing on average 5-6 d per wk over a period of $15 \mathrm{yr}$. Age, weight, and height (means \pm SD) for the males $(\mathrm{N}=6)$ were $28 \pm 6 \mathrm{yr}, 70 \pm 4 \mathrm{~kg}, 1.80 \pm 0.04$ $\mathrm{m}$, respectively, and for the females $(\mathrm{N}=7) 25 \pm 8 \mathrm{yr}$, $52 \pm 5 \mathrm{~kg}$, and $1.66 \pm 0.55 \mathrm{~m}$, respectively. Also included in this study are values from 1971 on the maximal oxygen uptake of another group of professional dancers performing for the same theatre. Their age, height, and weight for the males $(\mathrm{N}=5)$ were $29 \pm 10 \mathrm{yr}, 69 \pm 7$ $\mathrm{kg}$, and $1.77 \pm 0.03 \mathrm{~m}$, and for the females $(\mathrm{N}=6) 28$ $\pm 7 \mathrm{yr}, 51 \pm 3 \mathrm{~kg}$, and $1.64 \pm 0.03 \mathrm{~m}$, respectively. Each year group was composed of relatively equal proportions of soloists (including principal dancers) and members of the corps de ballet. Written informed consent was obtained from the subjects.

Oxygen uptake, heart rate, and blood lactic acid concentration. Each dancer's oxygen uptake-heart rate relationship was determined in the laboratory by employing two submaximal exercise intensities on a cycle ergometer (Monark, Sweden) and a maximal rate of exercise on a cycle ergometer (1971) or a treadmill (1983) with stepwise increases in intensity until the subject was exhausted. In order to compare the data on maximal oxygen uptake from 1971 with those from 1983, the individual values from 1971 were multiplied with the factor 1.065 (cf. 1). Heart rates were monitored with an electrocardiograph, using radio telemetry; oxygen uptake measurements were obtained by using the Douglas bag technique; and expired air was measured for volume in a balanced spirometer and analyzed for $\mathrm{O}_{2}$ and $\mathrm{CO}_{2}$ content by using the Haldane technique (1971) or using a mass spectrometer (1983) (MGA 200, U.K.). Fingertip blood samples for determination of the lactic acid concentration were obtained 1 and $3 \mathrm{~min}$ after the maximal exercise intensity and analyzed according to Barker-Summerson, slightly modified by Ström (1949). The oxygen uptake, heart rate and blood lactic acid concentration were also measured during the daily training of ballet technique ("class") as well as during choreographed dance. Portable equipment was used for the oxygen uptake determinations during dance (Figure 1). The daily classes of ballet at the theatre were composed of three distinct phases: I. Barre exercises; II. Center-floor exercises of moderate intensity; and III. Center-floor exercises of more severe 


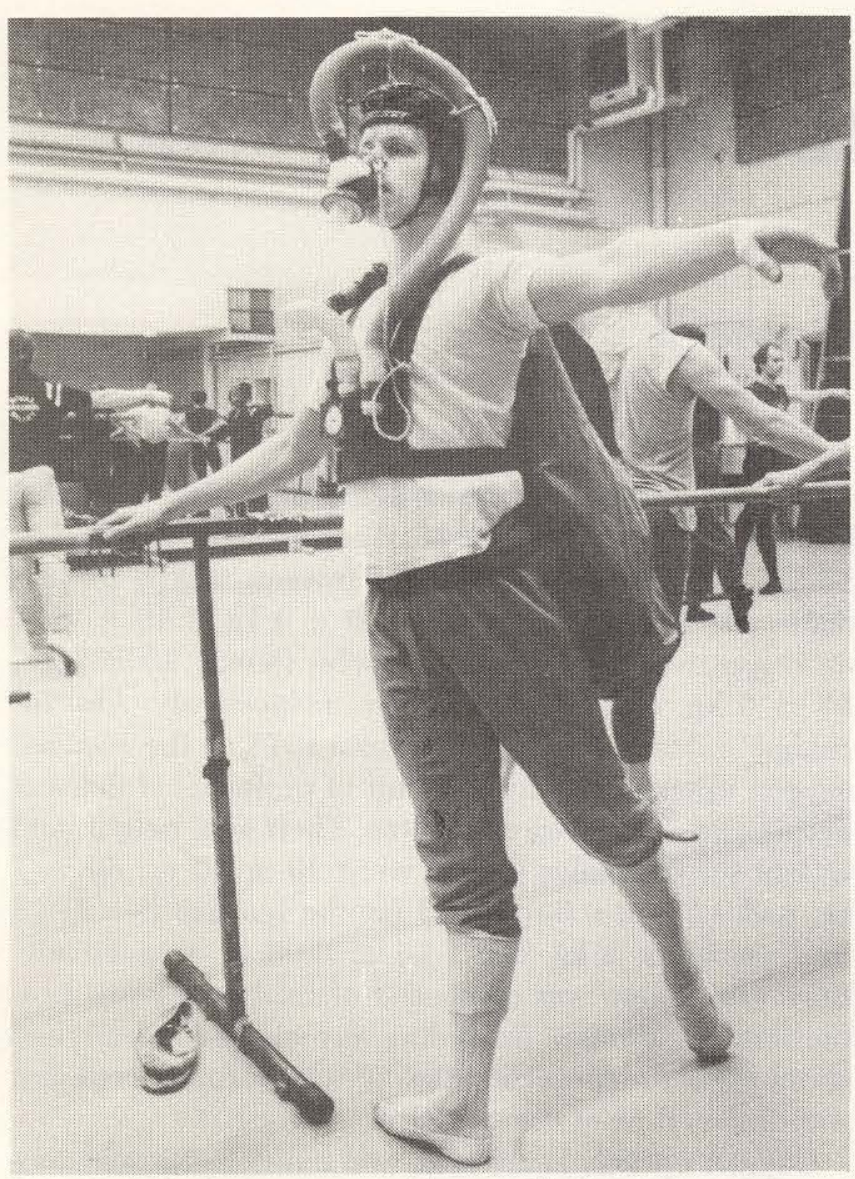

Figure 1-Ballet dancer adorned with a portable Douglas bag equipment for measurement of oxygen uptake.

intensity (the allegro part) with numerous aerial jumps and midair turns as well as travelling steps. The first two phases were characterized by each sequence of movements being performed twice in succession beginning alternately with the left and right extremities. During the third phase each sequence of movements was executed only once and then followed by a longer period of rest. The length of each sequence of movements and rest period was noted during each of the six different classes studied (see Results). The collection of expired air during phases I and II of the ballet classes began $5-10 \mathrm{~s}$ after initiation of the second performance of the movement series and continued until the performance terminated. During phase III, collection started $0-5 \mathrm{~s}$ after the beginning of each movement sequence and stopped at its completion. Collection of air was performed during every movement sequence, and the total volume (STPD) of air sampled was on the average $170 \pm 30$ liter (phase I), $105 \pm 30$ (phase II) and $135 \pm 50$ (phase III). Heart rate was recorded during every motion sequence. Presented values represent averages for each phase of the classes. Blood samples for lactate concentration analysis were taken approximately $30 \mathrm{~s}$ after each phase of the class. The lactate concentration in the blood $30 \mathrm{~s}$ after each phase mirrors the average concentration, because the duration of the phases was more than 20 min.
The median value for the length of the studied solo parts of choreographed dance was $1.8 \mathrm{~min}$ (1-12 $\mathrm{min}$ ) $(\mathrm{N}=10)$. Expired air was collected during the last $60 \mathrm{~s}$ (median value and range $=36-90$ ) and total volume (STPD) of air sampled averaged $90 \pm 15$ l. Blood samples for determination of blood lactate concentration were taken 1 and $3 \mathrm{~min}$ after the dance was terminated. The 10 different dances chosen were representative of moderately to very strenuous dance parts. They were from "Giselle," "Swan Lake," "Taming of a Shrew," "Variations for Four," (by A. Dolin), "Pulcinella" (by B. Cullberg and G. Carbone), and "Anecdote" (by L. Schubert). Heart rate and blood lactate concentration values were also measured at performance or final rehearsals of "Giselle," "Sleeping Beauty," "Les Noces" (by J. Robbins), and "Pulcinella" $(\mathrm{N}=5)$.

Statistics. Results are presented as mean \pm standard deviation (SD) or range. Differences between means for maximal oxygen uptake of the male and female soloists and members of the corps de ballet were tested for significance using Student's unpaired $t$-test.

\section{RESULTS}

The six different classes studied lasted 75 min each. Effective exercise time was about $30 \mathrm{~min}$, with $20 \mathrm{~min}$ spent on barre exercises and the rest on center-floor exercises. Average length of the movement sequences and rest periods were about 60 and $30 \mathrm{~s}$ (phase I), 35 and 85 $\mathrm{s}$ (phase II), and 15 and $75 \mathrm{~s}$ (phase III), respectively (Figure 2).

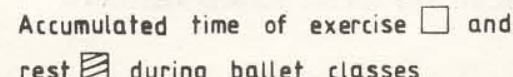

rest during ballet classes

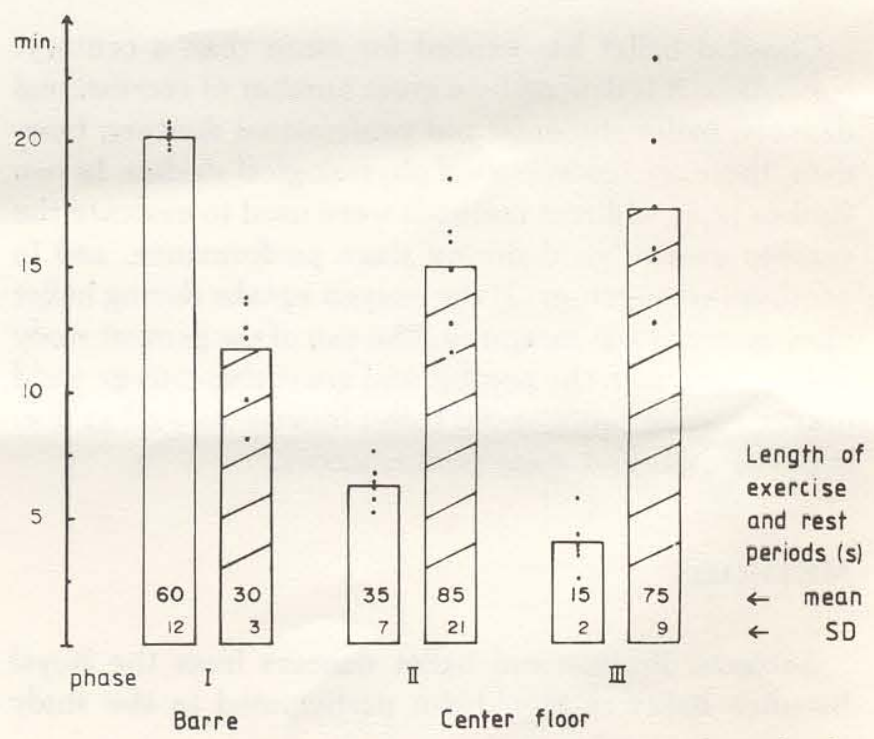

Figure 2-Bar graph of average total time of exercise and rest for the different phases of six classes. The dots represent the values for the different classes. 
Maximal oxygen uptake for the male dancers in 1971 was $3.8 \mathrm{l} \cdot \mathrm{min}^{-1}$ and $56 \mathrm{ml} \cdot \mathrm{min}^{-1} \cdot \mathrm{kg}^{-1}$ and in $1983,4.0$ $1 \cdot \mathrm{min}^{-1}$ and $57 \mathrm{ml} \cdot \mathrm{min}^{-1} \cdot \mathrm{kg}^{-1}$. Corresponding values for both groups of female dancers were $2.61 \cdot \mathrm{min}^{-1}$ and 51 $\mathrm{ml} \cdot \mathrm{min}^{-1} \cdot \mathrm{kg}^{-1}$ (Figure 3 ). The average maximal oxygen uptake was about $5 \%$ higher (n.s.) for the soloists than for the members of the corps de ballet.

The oxygen uptake during class averaged $36 \%$ (phase I), $43 \%$ (phase II), and $46 \%$ (phase III) of maximal oxygen uptake, respectively (Figure 4). The oxygen uptake during different solo parts of choreographed dance (variations or pas de deux) averaged $80 \%$ of maximum. A comparison of the measured oxygen uptake with that estimated from the heart rates during dance and the heart rateoxygen uptake relationship determined in the laboratory, revealed that the oxygen uptake relative to maximum would have been overestimated in absolute figures by $3 \%$ (range $=-9$ to 21) during barre exercises (i.e., average measured and estimated oxygen uptake during barre ex-

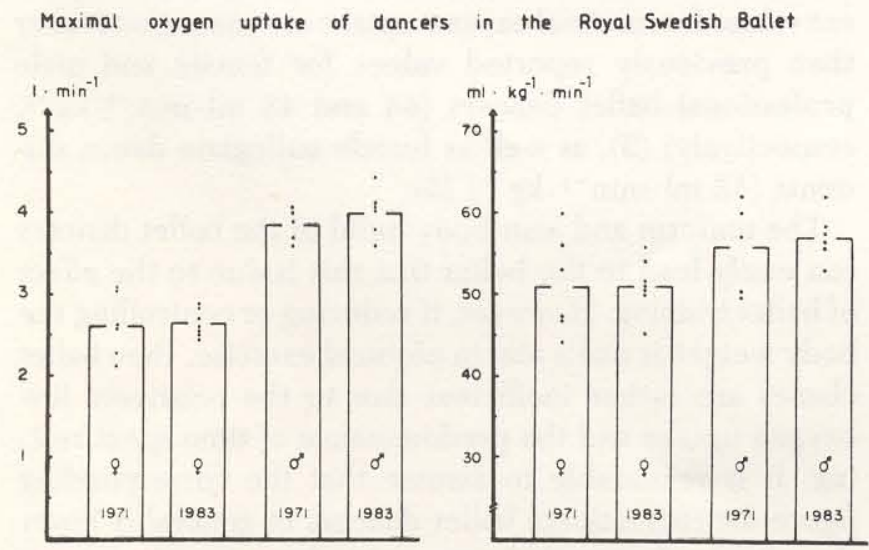

Figure 3-Maximal oxygen uptake of different groups of dancers in the Royal Swedish Ballet 1971 and 1983. Means and individual values.

Per cent of maximal oxygen uptake

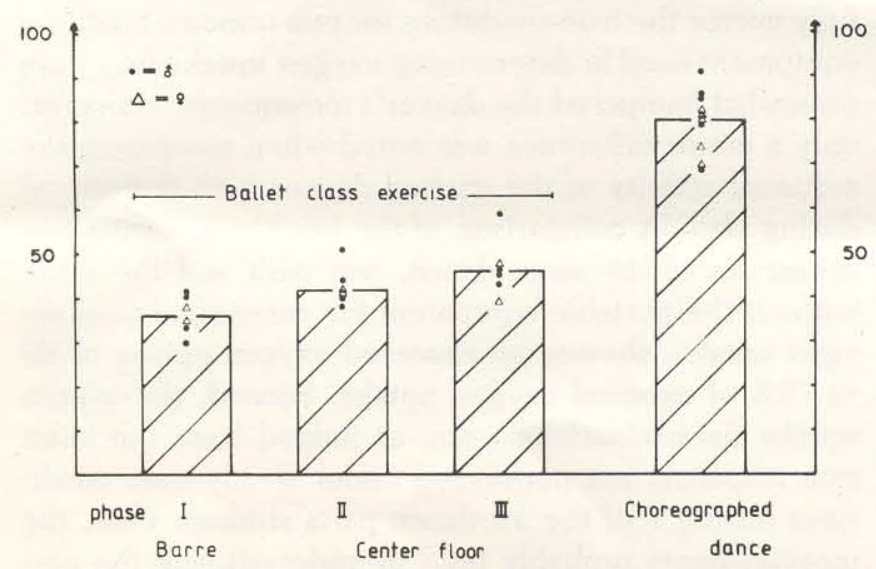

Figure 4-The relative oxygen uptake during ballet class exercise and rehearsed choreographed dance. Means and individual values. ercises was 36 and $39 \%$ of maximal oxygen, respectively), between $7 \%$ ( -9 to 21 ) (phase II) to $15 \%$ ( -1 to 21 ) (phase III) during center-floor exercises, and 6\% (-1 to 14) during composite dance, if heart rates were used for oxygen uptake calculations.

The blood lactate concentration values averaged $3 \mathrm{mM}$ during class. The average was $10 \mathrm{mM}$ after the variations or the pas de deux and $13 \mathrm{mM}$ after maximal treadmill running (Figure 5).

The heart rate was monitored and blood samples were obtained when solo parts $(\mathrm{N}=5)$ from different ballets ("Giselle," "Les Noces," "Sleeping Beauty," and "Pulcinella") were danced either as final rehearsals or performances. Heart rates were frequently close to maximum, and peak lactate values were of about the same magnitude as after maximal rates of exercise on cycle ergometer or treadmill, i.e., $11 \mathrm{mM}$. Two examples from these registrations are shown in Figures 6 and 7. A possible explanation of these high heart rates could be per-

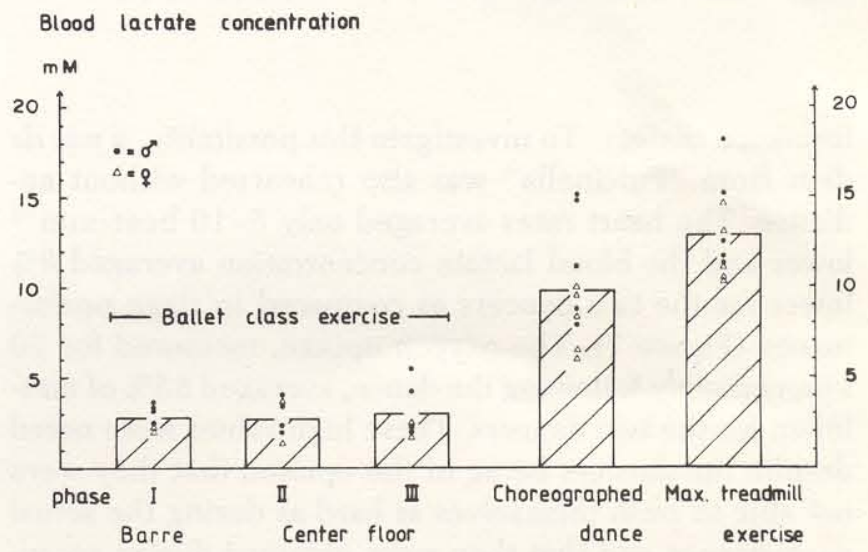

Figure 5-Blood lactate concentration in connection with ballet class exercise, rehearsed choreographed dance, and maximal physical effort. Means and individual values.

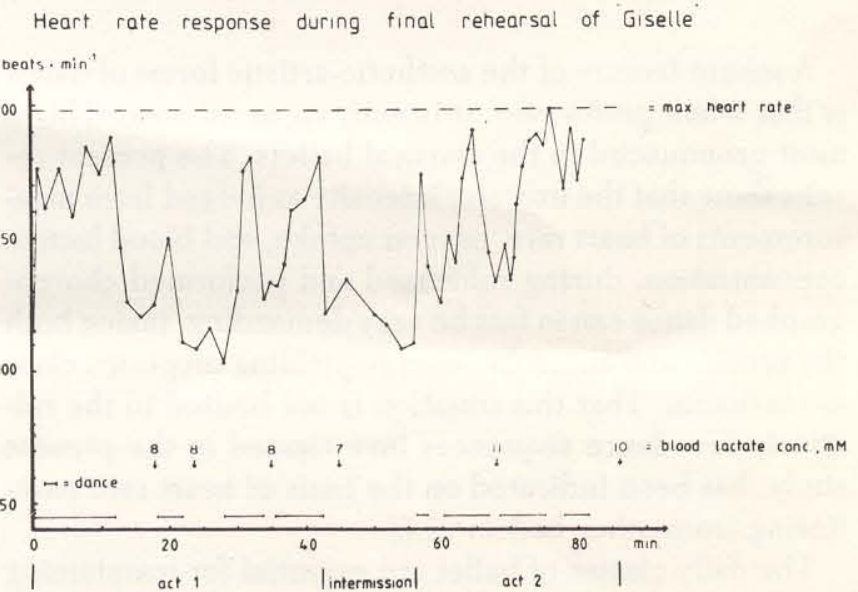

Figure 6-Heart rate response and blood lactate concentration of the female principal-part dancer in "Giselle" during a final rehearsal. The blood lactate concentration for the same dancer after maximal bicycle exercise was $11 \mathrm{mM}$. 


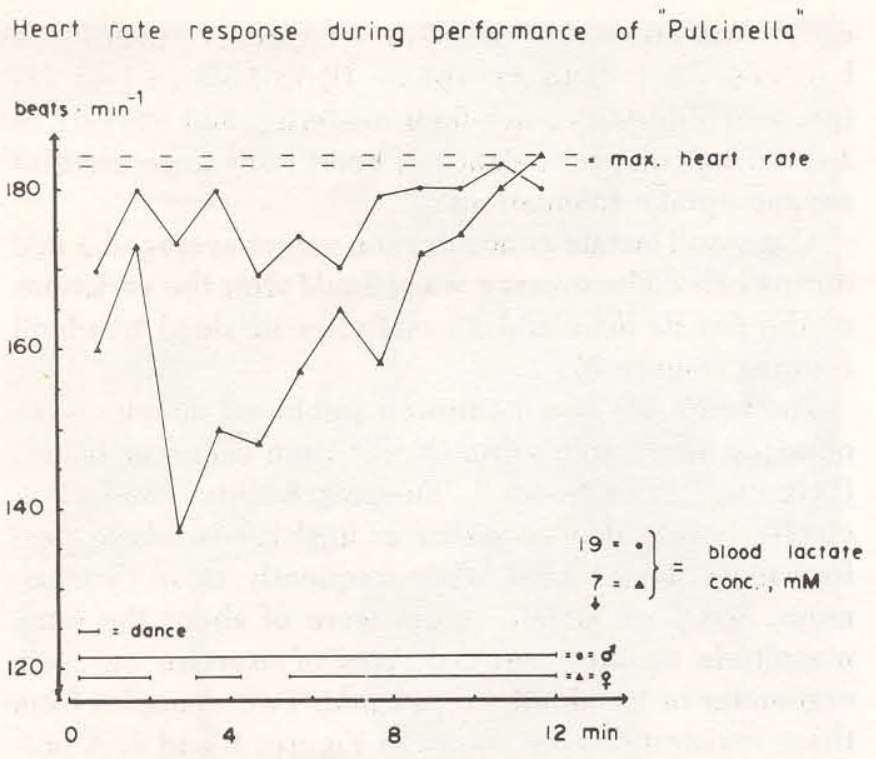

Figure 7-Heart rate response and blood lactate concentration of a female and male dancer during a pas de deux from the ballet "Pulcinella." The blood lactate concentration for the female and male dancer after maximal treadmill exercise was 10 and $15 \mathrm{mM}$, respectively.

formance anxiety. To investigate this possibility, a pas de deux from "Pulcinella" was also rehearsed without audience. The heart rates averaged only $5-10$ beat $\cdot \mathrm{min}^{-1}$ lower and the blood lactate concentration averaged $8 \%$ lower for the two dancers as compared to stage performance (Figure 7). The oxygen uptake, measured for 20 s immediately following the dance, averaged $85 \%$ of maximum for the two dancers. These high values were noted despite the dancers being of the opinion that they were not able to push themselves as hard as during the actual performance and that they were obtained during recovery.

\section{DISCUSSION}

A salient feature of the aesthetic-artistic forms of dance is that when performed, it is with apparent ease. This is most pronounced in the classical ballets. The present results show that the exercise intensity as judged from measurements of heart rate, oxygen uptake, and blood lactate concentration, during rehearsed and performed choreographed dance can in fact be very demanding, taxing both the aerobic and anaerobic energy-yielding processes close to maximum. That this situation is not limited to the relatively few dance sequences investigated in the present study, has been indicated on the basis of heart rate monitoring from other ballets $(2,6)$

The daily classes of ballet are essential for maintaining and developing the dancer's technique and coordination. The energetic demands during these training sessions stand in rather sharp contrast to those which can exist during stage performance. The average oxygen uptake during class was about $40 \%$ of maximal oxygen uptake, which is rather close to that reported for different ballet class exercises by Cohen et al. (3). The motional intensity during the center-floor exercises was frequently very high, but the exercise periods were too short to evoke any high and prolonged strain on the circulatory system, a prerequisite for effective training of this organ system. Even if the aerobic-energy yield can be very high during choreographed dance, it is usually so only for rather brief periods (a few minutes, cf. 2) with longer periods of rest in between. Furthermore, these loads are not imposed frequently on the dancers. Thus, the relatively low maximal oxygen uptakes of the dancers, 51 and 57 $\mathrm{ml} \cdot \mathrm{min}^{-1} \cdot \mathrm{kg}^{-1}$ for the females and males, respectively, might be expected as none of the dancers were engaged in endurance training. Nearly the same oxygen uptake values were noted in another group of dancers employed by the same theatre $12 \mathrm{yr}$ previous (1971). This indicates that there has been no trend emphasizing aerobic training in the dancers' activities during the last decade. The present values for maximal oxygen uptake are somewhat higher than previously reported values for female and male professional ballet dancers ( 44 and $48 \mathrm{ml} \cdot \mathrm{min}^{-1} \cdot \mathrm{kg}^{-1}$, respectively) (3), as well as female collegiate dance students $\left(42 \mathrm{ml} \cdot \mathrm{min}^{-1} \cdot \mathrm{kg}^{-1}\right)(5)$.

The uniform and lean-body build of the ballet dancers can easily lead to the belief that this is due to the effect of ballet training. However, if reducing or controlling the body weight is one's aim in physical exercise, then ballet classes are rather inefficient due to the relatively low oxygen uptake and the predominance of time spent resting. It is reasonable to assume that the corresponding figure for recreational ballet dancers in general is lower than for professionals because it takes several years of daily classical schooling before advanced technique, and its attendant higher motional activity, is achieved. This is so even if the unskilled dancer executes the ballet exercises in a less economical fashion, as indicated by Ferland et al. (4).

It is possible that measurements and estimates do not fully mirror the true conditions for two reasons. First, the equipment used in determining oxygen uptake may have somewhat hampered the dancer's movements. However, only a minor difference was noted when comparing the motional activity of the studied dancer with the others' during class. A comparison of the heart rate during two rehearsals of the same dance, one with and the other without the portable equipment for measurement of oxygen uptake, showed an expected oxygen uptake of 69 vs $75 \%$ of maximal oxygen uptake. Second, the oxygen uptake determinations were, as judged from the heart rate response, not performed under steady-state conditions during 7 of the 10 dance parts studied. Thus, the measurements probably tend to underestimate the normal exercise intensity during class and dance. However, 
even with inaccuracies taken in consideration, the above interpretation is likely valid.

In conclusion, classical ballet is a predominantly intermittent type of exercise. In choreographed dance each exercise period usually lasts only a few minutes, but can be very demanding energetically, while during the dancer's basic training sessions the energy yield is low.

\section{REFERENCES}

1. Ȧstrand, P.-O. and K. Rodahl. Textbook of Work Physiology, 2nd Edition. New York: McGraw-Hill, 1977, p. 335.

2. COHEN, J., K. SEGAL, and W. MCARDLE. Heart rate response to ballet stage performance. Phys. Sportsmed. 10(11):120-133, 1982.

3. COHEN, J., K. SEGAL, I. WITRIOL, and W. MCARDLE. Cardiorespiratory responses to ballet exercise and the $\dot{V}_{2 \max }$ of elite ballet dancers. Med. Sci. Sports Exerc. 14:212-217, 1982.

4. FERLAND, G., P. GARDINER, and R.-M. LĖBE-NÉRON. Analysis of the electromyographic profile of the rectus femoris and biceps femoris
The authors gratefully acknowledge D. Rydholm, J. Delisle, and G. Roempke at the Royal Swedish Ballet for their coordinative assistance, I. Hallbäck, A.-R. Kakko-Westin, E. Karlsson, and L. Rydén for their technical assistance, as well as U. Siltberg for secretarial assistance. We are indebted to the subjects, the dancers, for their positive participation. We also acknowledge the expertise of R. Hill, J. Salier, and A. Way. Furthermore, we are grateful to C. Mudry, L. Sterbinsky, and T. Vasary, the teachers of the classes studied. This study was supported by the Royal Swedish Ballet and the Research Council of the Swedish Sports Federation. during the "demi-plie" in dance. Med. Sci. Sports Exerc. 15:159, 1983. (Abstract)

5. NovaK, L., L. MAGILL, and J. SChUTTE. Maximal oxygen intake and body composition of female dancers. Eur. J. Applied Physiol. 39:277$282,1978$.

6. Seliger, V., J. Glúcksmann, J. Pachlopnik, and I. Pachlopnikova. Evaluation of stage artist's activities on basis of telemetrical measurements of heart rates. Int. Z angew. Physiol. 228:86-104, 1970.

7. STROM, G. The influence of anoxia on lactate utilization in man after prolonged muscular work. Acta Physiol. Scand. 17:440-451, 1949. 